\title{
Escala de apego à moradia em área de risco: construção e evidências baseadas no conteúdo
}

\author{
Hazardous housing attachment scale: construction and evidence \\ based on content
}

Roberta Borghetti Alves', Ariane Kuhnen², Roberto Moraes Cruz ${ }^{\mathbf{2}}$

DOI: 10.1590/0103-11042019S310

RESUMO A pesquisa visou construir uma escala de apego à moradia em área de risco e buscou evidências de validade baseada no conteúdo dos itens. Para a sua construção, utilizou-se o modelo tripartite de Scannell e Gifford, o qual entendem que o apego ao lugar é formado pelos fatores pessoa, lugar e processo psicológico. Foram elaboradas 68 afirmativas de autorrelato em uma escala tipo Likert de 5 pontos, na qual se realizou a análise de juízes por 7 pós-graduandos da área e a análise semântica por 30 pessoas que residiam em área suscetível à ocorrência de enchente e/ou deslizamento. Para a análise de juízes, utilizou-se a Razão de Validade de Conteúdo em que 36 itens foram considerados como relevantes $(\mathrm{RVC}=1,0)$; e 32, como irrelevantes ( $\mathrm{RVC}=-0,42 \mathrm{a}$ $-0,14$ ), sendo estes excluídos. Já na análise semântica, 35 itens foram avaliados como claros, e em 1 foi alterada a escrita. Três foram excluídos por não representar características da população ou tender o resultado. A escala preliminar obteve 33 itens com evidências de validade baseada no conteúdo itens. Identificaram-se fragilidades no modelo teórico tripartite utilizado para entendimento do construto de modo a necessitar sua testagem empírica. Sugerem-se estudos que busquem outras evidências de validade e indícios de precisão.

PALAVRAS-CHAVE Afeto. Psicometria. Psicologia ambiental. Reprodutibilidade dos testes. Habitação.

ABSTRACT The research aimed to build a hazardous housing attachment scale and sought evidence of validity based on the content of the items. For its construction, it used the tripartite model of Scannell and Gifford, who understand that attachment to a place is formed by the factors: person, place, and psychological process. Sixty-eight self-reported statements were elaborated on a five-point Likert scale, where the analysis of judges by seven postgraduates of the field and the semantic analysis by thirty people residing in an area susceptible to flooding and/or landslides. For the analysis of judges, we used the Content Validity Ratio where 36 items were considered as relevant $(R V C=1.0)$ and 32 as irrelevant $(R V C=-0.42$ to -0.14), which were excluded. In the semantic analysis, 35 items were evaluated as clear and in one the writing was altered. Three were excluded because they did not represent population cha-

1 Universidade do Vale do Itajaí (Univali) - Itajaí (SC), Brasil.

roberta_alves@univali.br

2 Universidade Federal de Santa Catarina (UFSC) -

Florianópolis (SC), Brasil. racteristics or tend the result. The preliminary scale obtained 33 items with evidence of validity based on content items. Weaknesses were identified in the tripartite theoretical model and used to understand the construct in a way that it requires its empirical testing. Studies are suggested that seek other evidence of validity and evidence of accuracy.

KEYWORDS Affect. Psychometrics. Environmental psychology. Reproducibility of results. Housing. 


\section{Introdução}

Em janeiro de 2010, na Região Serrana do Rio de Janeiro, ocorreu um dos maiores deslizamentos do Brasil'. Moradores fugiam e escondiam-se em uma mata enquanto chegavam os helicópteros que traziam os mantimentos. Neles, pairava o temor de serem removidos de suas moradias ${ }^{2}$. Profissionais que atuavam na Defesa Civil, naquele momento, alertavam as pessoas a deixarem as suas residências devido ao risco de acidentes fatais, mas elas permaneciam na moradia. Essas situações ocorrem diversas vezes no País. Jornais e noticiários trazem reportagens sobre pessoas que quiseram permanecer na casa após algum desastre. No debate sobre essa temática, o discurso técnico confronta-se com as práticas cotidianas das pessoas que residem em áreas suscetíveis à ocorrência de desastres, consideradas como áreas de risco.

Avalia-se como área de risco quando há a probabilidade de um determinado fenômeno climático oferecer perigo às pessoas e aos lugares que residem, os quais apresentam irregularidades para sua ocupação, tais como: ausência de saneamento básico, acúmulo de lixo, moradia localizada perto de encosta ou margem do rio $^{3}$. A relação entre essas características contribui para suscetibilidade ao desastre. Neste trabalho, o termo utilizado para desastre natural será desastre socioambiental, por entender que há um conjunto de fatores que contribuem para sua ocorrência, desde a vulnerabilidade da população ${ }^{4}$, até a ocupação humana do ambiente, o material utilizado para a construção da moradia, a gestão integral do risco municipal, entre outros.

Dessa forma, compreende-se o desastre socioambiental como o impacto causado por fenômenos naturais extremos ou intensos (seca, enchentes, entre outros) sobre um sistema social, que ocasiona prejuízos que excedem a capacidade de a comunidade atingida lidar com tal desastre ${ }^{5}$. Esse desastre afeta muitas pessoas e traz diversos impactos, seja sob o aspecto dos danos físicos sofridos, seja por perdas materiais, ou, ainda, pelos danos psicológicos diante das perdas vivenciadas ${ }^{6}$, de modo a ser compreendido dentro de um contexto social, político e econômico no qual ele ocorre ${ }^{7}$.

Diante do debate acerca das áreas de risco, as pessoas que residem nesses locais são trazidas à tona. Tal população cria vínculos, associa histórias e momentos com a moradia, de modo a apegar-se a esse lugar e, assim, colocar o risco como plano secundário em suas vidas ${ }^{8}$. O apego ao lugar é um objeto de estudo complexo da Psicologia Ambiental, subárea da Psicologia que estuda as interrelações entre a pessoa e o ambiente ${ }^{9}$.

Nesta pesquisa, compreende-se o referido construto por meio do modelo teórico tripartite proposto por Scannell e Gifford ${ }^{10}$ que parte da premissa que o apego ao lugar é um fenômeno multifacetado. Ele é formado pelo vínculo de uma pessoa ou de um grupo com o lugar e pode variar em termos de especificidade, nível espacial e características físicas e/ou sociais 9 . O apego ao lugar passa a ser entendido como um fenômeno formado pela pessoa, a qual tem o apego, o lugar que é o local onde foi estabelecido o vínculo e o processo psicológico que seria a manifestação deste apego ${ }^{10}$. A dimensão pessoa passa a ser entendida a partir dos aspectos culturais/ grupais e aspectos individuais. O lugar parte de suas características físicas e sociais. Ademais, o processo psicológico será expresso por meio dos aspectos afetivos, cognitivos e comportamentais.

Diante da delimitação do apego ao lugar, salienta-se a importância de haver em âmbito nacional uma medida para mensurá-lo. A existência de tal medida poderia favorecer a avaliação do modelo teórico, realizar testes empíricos de hipóteses, assim como obter respostas ante a população que reside em área de risco, avaliar a efetividade ou propor intervenções diante dos escores dos participantes ${ }^{11}$. Para que o instrumento possa ser utilizado, precisa haver evidências de validade e precisão. Uma das primeiras fontes de informação da validade baseia-se no conteúdo dos itens. Nesse tipo de evidência, analisa-se o conteúdo das afirmações de modo a verificar se há representatividade das características e dos comportamentos que são apresentados no modelo teórico do construto por meio da análise de pesquisadores experientes na área, assim 
como analisa-se a clareza dos itens na perspectiva da população-alvo do instrumento ${ }^{12}$.

Diante do que foi salientado, a fim de comprovar a relevância científica desta pesquisa, realizou uma pesquisa nos últimos dez anos nos Portais Biblioteca Virtual de Psicologia e Capes com os descritores 'apego ao lugar', 'instrumento de medida', 'escala', 'inventário', 'validade', 'confiabilidade' e suas respectivas terminologias em inglês, a fim de verificar a produção científica atual dedicada aos instrumentos de apego ao lugar. Encontram-se somente dois estudos internacionais que elaboraram uma escala de apego ao lugar e relataram a evidência baseada no conteúdo dos itens. No entanto, nenhum deles utilizou o modelo teórico tripartite deste estudo. Dessa forma, ressalta-se a importância desta pesquisa, bem como a necessidade de serem construídos instrumentos de medida sobre o apego com evidência de validade e adequados ao contexto sociocultural do Brasil. Além disso, a publicação desta pesquisa contribui para os pesquisadores que almejam construir escalas com evidências de validade de conteúdo e que não têm conhecimento das etapas a serem realizadas. Dadas essas considerações, este estudo objetivou construir uma escala de apego à moradia em área de risco, assim como buscou evidências baseadas no conteúdo dos itens de modo que tais afirmações tivessem uma equivalência semântica e contextual.

\section{Métodos}

\section{Delineamento}

Considerou-se esta pesquisa de natureza aplicada, pois visou produzir conhecimento científico com a finalidade de aplicação imediata ${ }^{13}$. Foi construída uma escala voltada ao apego à moradia de pessoas que residem em área de risco em que se buscou evidências de validade de conteúdo do instrumento. Esta pesquisa caracterizou-se como descritiva. O construto foi observado de modo indireto por meio de pesquisa teórica e de campo ${ }^{\mathbf{1 4}}$, na qual foi realizada a análise de juízes e análise semântica dos itens da escala com pessoas que residem em área de risco. Para a construção dos itens da escala e para a análise semântica, adotou-se uma análise qualitativa; e para avaliar a concordância dos juízes, foram aplicados procedimentos de estatística descritiva ${ }^{15}$. Abaixo, segue a descrição utilizada para a elaboração da escala.

\section{Procedimentos teóricos para elabo- ração da escala}

O processo de elaboração do instrumento foi caracterizado como circular e que envolveu diferentes etapas. A fim de clarificar todas as etapas, foi realizada uma divisão, unicamente pedagógica, a fim de visualizar e sistematizar o método de trabalho ${ }^{16}$. Para tal elaboração, foram seguidos os passos recomendados por Pasquali17. O primeiro deles foi a delimitação do construto, como visto a seguir:

$1^{\text {a) }}$ etapa - definição do construto, no qual se realizou o detalhamento sobre o fenômeno apego ao lugar ${ }^{16}$ por meio do modelo teórico tripartite de Scannell e Gifford ${ }^{10} .2^{\mathrm{a}}$ ) Delimitação do universo de fenômeno, na qual foram descritas as características do construto, por meio das dimensões do construto, sendo elas: a pessoa, o lugar e o processo psicológico. A dimensão pessoa subdivide-se em aspectos culturais/ grupais e aspectos individuais. A dimensão lugar subdivide-se nas subdimensões física e o social. A dimensão de processos psicológicos subdivide-se nas facetas afetiva, cognitiva e comportamental. $3^{a}$ ) Definição da representatividade de construto, em que se delimitou a proporção com que cada dimensão será representada na escala de modo que foram elaborados, no mínimo, 20 itens para cada fator, sendo eles: a pessoa, o lugar e o processo psicológico. $4^{\mathrm{a}}$ ) Elaboração de um quadro de especificação, em que deveria constar o construto com suas respectivas dimensionalidades e características ${ }^{17}$, conforme pode ser evidenciado no quadro 1. Tal quadro contribuiu para que os pesquisadores elaborassem os itens de acordo com as características do construto. 
Quadro 1. Síntese do modelo teórico tripartite de Scannell e Gifford

\begin{tabular}{|c|c|c|c|}
\hline Construto & Dimensão & Subdimensões & Características \\
\hline \multirow[t]{7}{*}{ Apego ao lugar } & Pessoa & Aspectos Individuais & $\begin{array}{l}\text { Experiências, realizações pessoais, marcos, } \\
\text { metas. }\end{array}$ \\
\hline & & Aspectos Culturais/Grupais & $\begin{array}{l}\text { Valores, aspecto religioso, cultural, familiar, } \\
\text { rituais. }\end{array}$ \\
\hline & Lugar & Físico & $\begin{array}{l}\text { Características físicas, aspectos simbólicos } \\
\text { do lugar. }\end{array}$ \\
\hline & & Social & $\begin{array}{l}\text { Área social do lugar, laços sociais, interação } \\
\text { social, vizinhança. }\end{array}$ \\
\hline & Processo Psicológico & Afeto & $\begin{array}{l}\text { Felicidade, orgulho, amor, medo, contenta- } \\
\text { mento e ambivalência. }\end{array}$ \\
\hline & & Cognição & $\begin{array}{l}\text { Memória, conhecimento, pensamento e } \\
\text { crenças. }\end{array}$ \\
\hline & & & $\begin{array}{l}\text { Proximidade, manutenção, reconstrução do } \\
\text { lugar e desejo de permanecer no lugar. }\end{array}$ \\
\hline
\end{tabular}

Fonte: Scannell e Gifford $\mathbf{1 0}^{0}$

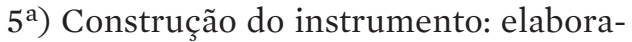
ram-se os itens que representaram os atributos do construto. A construção dos itens seguiu os critérios propostos por Pasquali18:

a) Critério comportamental: os itens descrevem o comportamento em si, e não o construto. b) Desejabilidade: os itens não sugerem ou dão a entender ao participante respostas certas ou erradas; c) Simplicidade: os itens buscaram ser escritos de forma clara, de modo a evitar ambiguidade, assim como apresentaram apenas uma característica do construto d) Clareza: as afirmações buscaram ser entendidas pelos diferentes estratos de escolaridade dos participantes; e) Relevância: todo item foi construído com base no conhecimento científico de modo a atender ao foco da pesquisa; f) Precisão: cada item tentou mensurar de forma precisa o comportamento investigado; g) Variedade: os itens elaborados buscaram evitar a monotonia e a tendenciosidade de quem irá respondê-los.

No que consiste às dimensões do construto, Pasquali18 propõe dois critérios:

a) Amplitude: o conjunto de itens referentes a uma dimensão buscou representar todas as características desse atributo; b) Equilíbrio: os itens que contemplaram cada dimensão foram elaborados com diferentes níveis de dificuldade.

\section{Procedimentos empíricos}

\section{ANÁLISE DE JUÍZES}

Após a elaboração dos itens, a escala foi submetida à análise de juízes, a qual se referia à avaliação dos itens por pesquisadores ou profissionais que possuíam conhecimento, no que concerne à Psicometria, à elaboração de instrumento de medida ${ }^{\mathbf{1 8}}$ e ao fenômeno de mensuração. Neste estudo, foram convidados sete estudantes de um Programa de Pós-Graduação do Curso de Psicologia de uma Universidade Federal do Sul, dos quais quatro faziam parte de um Laboratório de Psicologia Ambiental e possuíam conhecimento acerca do objeto de estudo, e três integravam um Laboratório que possuía experiência em construção de instrumentos de medida.

Para os juízes, foi enviado um documento em Word ${ }^{\circledR}$ via $e$-mail, para que pudessem efetuar a análise em seu tempo e local de preferência. Ele continha a definição do construto apego ao lugar, adotada nesta pesquisa, acompanhada da definição de cada uma das três dimensões e de suas respectivas subdimensões. Posteriormente, havia uma tabela contendo os 68 itens elaborados 
e randomicamente ordenados. Nela havia os itens, os cinco pontos da escala tipo Likert, uma coluna para colocar o nome da referida dimensão e subdimensões, outra coluna para avaliar item e, por fim, a última coluna, que foi intitulada 'observações', a fim de que os juízes pudessem dar sugestões de melhoria, tanto para o item quanto para o formato da escala. Na coluna voltada à avaliação do item, os avaliadores tiveram que assinalar uma das categorias, 'se o item era essencial' enquanto mensuração do fenômeno, 'útil, porém não essencial' ou 'não necessário'19.

Nessa etapa, buscou-se verificar a pertinência de cada item na mensuração do construto, correspondência da afirmação à dimensionalidade proposta e clareza das informações. Nessa análise, investigou-se primeiramente a Razão de Validade de Conteúdo (RVC) de modo a verificar a quantidade de concordância observada pelos juízes quanto à pertinência deles. Como se tratava de sete juízes, adotou-se o valor mínimo da RVC de $0,99^{20}$ a fim de que tal concordância não ocorresse por acaso. Depois dessa análise, verificou-se o Kappa de Cohen (k) de modo a identificar a magnitude da concordância dos juízes sobre as dimensões e subdimensões do construto. A referida análise avalia o grau de acordo e, consequentemente, a confiabilidade da classificação. O resultado de Kappa varia de -1 a 1, sendo este analisado da seguinte maneira: $\mathrm{k}<0$ : indica que não houve concordância entre os juízes; $0 \leq \mathrm{k}<0,21$ : ínfima concordância; $0,21 \leq \mathrm{k}<0,41$ : fraca; $0,41 \leq \mathrm{k}<0,61$ : moderada; $0,61 \leq \mathrm{k}<0,81$ : substancial; $0,81 \leq \mathrm{k}$ $\leq 1,00$ : quase perfeita ${ }^{21}$. Entre as possibilidades de índices de acordo interjuízes, o coeficiente Kappa de Cohen tem sido um dos mais utilizados na literatura, pois considera a probabilidade de haver concordância ao acaso para diminuir o valor obtido 22 .

\section{ANÁLISE SEMÂNTICA}

Após a análise de juízes, foi realizada a análise semântica por pessoas que compunham a população-alvo do instrumento de medida.
Com essa análise, buscou-se verificar a clareza dos itens para que pessoas com menor grau de escolaridade consigam compreender o instrumento. Para tanto, a escolha dos participantes foi do tipo intencional, composta por procedimento não probabilístico, uma vez que foram estabelecidos critérios de inclusão para os participantes ${ }^{23}$. Destacam-se os critérios: a) morar em uma área considerada de muito alto, alto ou médio risco considerado pelo Serviço Geológico do País; b) possuir a idade mínima de 18 anos no momento da coleta de dados, pois os sujeitos menores estão sob a tutela legal dos pais, e podem não ter autonomia e/ ou independência (financeira) suficiente para decidirem o lugar para morar. Ressalta-se que, nesta pesquisa, não houve preferência entre sujeitos casados e solteiros, homens ou mulheres, pois, de acordo com Ruiz, Villodres e Vilela ${ }^{24}$, ambos são suscetíveis ao apego ao lugar. Foi pesquisado um participante por moradia, de modo a aplicar a escala com quem estivesse presente no momento da coleta de dados.

Inicialmente, foi explicada a pesquisa; em seguida, mediante $\mathrm{o}$ aceite e assinatura em duas vias do Termo de Consentimento Livre e Esclarecido (TCLE), a escala foi aplicada na moradia do participante. Os pesquisadores colocaram-se à disposição para realizar a leitura e o preenchimento da escala caso fosse de interesse do participante. Nessa etapa, foi solicitado aos participantes ofeedback acerca da clareza e da compreensão das instruções, do conteúdo dos itens e da escala apresentada ${ }^{23}$. Além disso, foi avaliado se as respostas dos participantes davam efeito teto ou efeito chão, ou seja, se as respostas tendiam no mínimo $80 \%$ para um ponto extremo (concordo totalmente ou discordo totalmente). Para isso, foi realizada a análise da média e da porcentagem de respostas por cada item. Esta análise contribui para verificação de itens não discriminatórios, assim como para avaliar o entendimento da população perante o tipo de escala utilizada.

Desse modo, participaram da análise semântica 30 pessoas que residem em área de muito alto e alto risco pertencentes à cidade de 
Brusque e Itajaí, localizadas na Região do Vale do Itajaí, Santa Catarina. Em ambas as cidades, o Serviço Geológico do País conta com o auxílio da Defesa Civil e do Centro Universitário de Estudos e Pesquisas sobre Desastres (Ceped) da Universidade Federal de Santa Catarina (UFSC), os quais já haviam realizado o mapeamento das principais áreas de risco, o que contribuiu para a realização desta pesquisa.

\section{CUIDADOS ÉTICOS}

Salienta-se que esta pesquisa foi aprovada pelo Comitê de Ética em Pesquisas com Seres Humanos da UFSC (CAAE: 64632016.4.0000.0121). Os participantes da análise semântica, além de assinarem o TCLE, foram informados quanto ao anonimato dos dados, ao aspecto voluntário de sua participação, aos riscos e aos benefícios da pesquisa, bem como sobre a possibilidade de desistência em qualquer momento da pesquisa.

\section{Resultados}

Foi elaborada uma escala de apego à moradia em área de risco com 68 itens, que indicaram afirmativas de autorrelato que deveriam ser respondidas em uma escala tipo Likert de 5 pontos, indo do 1-Discordo totalmente ao 5-Concordo totalmente. Buscou-se elaborar, no mínimo, 20 itens para cada fator ${ }^{18}$ a fim de haver uma ampla representatividade dos atributos do construto. Desse modo, foram criados: 21 itens para dimensão lugar, sendo 13 itens voltados às características físicas, e 8, para as sociais; 22 itens para a dimensão pessoa, sendo 10 para os aspectos pessoais e 12 para as características culturais; e 25 itens para a dimensão processo psicológico, dos quais 10 itens se referiram à cognição, 9, ao comportamento, e 6, ao afeto.

\section{Análise dos juízes}

Os juízes analisaram o conteúdo dos itens e a dimensão e a subdimensão que se enquadravam. Inicialmente, foi verificada a RVC entre os juízes, ou seja, o quão importante e essencial era o item para mensuração do construto e para a escala. Adotou-se o critério de valor mínimo de RVC de 0,9919. Abaixo, segue o quadro 2 em que constam primeiramente a dimensão e a subdimensão de cada afirmação da escala apego ao lugar, o item em si e resultado de seu RVC.

\begin{tabular}{llc}
\hline Quadro 2. Índice de RVC entre os juízes de acordo com a dimensão e subdimensão do apego ao lugar & RVC \\
\hline $\begin{array}{l}\text { Dimensão: Subdi- } \\
\text { mensão }\end{array}$ & Número do Item & $-0,14$ \\
\hline $\begin{array}{l}\text { Pessoa: aspectos } \\
\text { individuais }\end{array}$ & EAM 4- Moro nessa casa para não depender financeiramente de outras pessoas. & $-0,14$ \\
& EAM 10- Me sinto independente morando nessa casa. & $-0,14$ \\
& EAM 12- Esta é a única casa que tenho para morar & 1,0 \\
& EAM 25- Essa casa foi onde construí uma família & 1,0 \\
& EAM 42- Para mim, ter esta casa é a realização de um sonho. & $-0,14$ \\
& EAM 45- Moro nessa casa para não pagar aluguel. & 1,0 \\
& EAM 57- Essa casa é o único bem que tenho. & $-0,14$ \\
& EAM 62- Moro nessa casa porque consigo pagar as despesas. & 1,0 \\
& EAM 63- Esta foi minha primeira casa própria & $-0,14$
\end{tabular}




\section{Quadro 2. (cont.)}

\begin{tabular}{|c|c|c|}
\hline \multirow{12}{*}{$\begin{array}{l}\text { Pessoa: aspectos } \\
\text { culturais }\end{array}$} & EAM 8- Durante a enchente ou o deslizamento ajudamos uns aos outros. & 1,0 \\
\hline & EAM 13- É meu destino morar nessa casa. & 1,0 \\
\hline & EAM 15- Avisamos uns aos outros quando a água é cortada. & 1,0 \\
\hline & EAM 17- As pessoas que moram comigo acreditam que devemos permanecer aqui. & $-0,14$ \\
\hline & EAM 28- Deus protege minha casa. & $-0,42$ \\
\hline & $\begin{array}{l}\text { EAM 31- Temos o costume de ajudar uns aos outros quando ocorre enchente ou } \\
\text { deslizamento. }\end{array}$ & $-0,42$ \\
\hline & EAM 33- Essa casa é um presente de Deus. & 1,0 \\
\hline & EAM 35- Avisamos uns aos outros quando a Defesa Civil chega ao bairro. & $-0,14$ \\
\hline & EAM 43- Cuidamos uns das casas dos outros. & $-0,14$ \\
\hline & EAM 51- Deus me deu forças para reconstruir a minha casa. & 1,0 \\
\hline & EAM 54- Posso praticar minha religião em minha casa. & $-0,42$ \\
\hline & EAM 64- Abrigamos uns aos outros quando ocorre enchente ou deslizamento. & $-0,42$ \\
\hline \multirow{8}{*}{$\begin{array}{l}\text { Lugar: aspectos } \\
\text { sociais }\end{array}$} & EAM 6- Morar aqui me faz sentir parte dessa comunidade. & 1,0 \\
\hline & EAM 9- As pessoas que são importantes pra mim moram nessa comunidade. & 1,0 \\
\hline & EAM 21- Me sinto próximo das pessoas que moram nessa casa. & $-0,42$ \\
\hline & EAM 27- As pessoas do meu bairro controlam a vida uns dos outros. & 1,0 \\
\hline & EAM 34- A maioria das pessoas que eu conheço moram nesse bairro. & 1,0 \\
\hline & EAM 39- Meus familiares moram perto da minha casa. & 1,0 \\
\hline & EAM 49- Posso contar com a ajuda dos meus vizinhos. & $-0,14$ \\
\hline & EAM 53- Posso receber amigos e familiares em minha casa. & 1,0 \\
\hline \multirow{13}{*}{$\begin{array}{l}\text { Lugar: aspectos } \\
\text { físicos }\end{array}$} & EAM 2- Para mim é importante morar perto do centro. & 1,0 \\
\hline & EAM 3- Considero frágil a estrutura física da minha casa. & 1,0 \\
\hline & EAM 5- Tenho espaço para aumentar a casa onde moro. & 1,0 \\
\hline & EAM 11- Para mim é importante morar em um lugar silencioso. & $-0,14$ \\
\hline & EAM 14- A temperatura dentro da minha casa é agradável. & 1,0 \\
\hline & EAM 18- A localização dessa casa me deixa insegura & 1,0 \\
\hline & EAM 19- Para mim é importante morar perto dos lugares que frequento. & 1,0 \\
\hline & EAM 24- Considero importante ter esgoto tratado em minha casa. & 1,0 \\
\hline & EAM 30- Sinto cheiro de esgoto quando estou em casa. & 1,0 \\
\hline & EAM 41- Considero importante ter água tratada em minha casa. & 1,0 \\
\hline & EAM 44- Minha casa é muito pequena. & 1,0 \\
\hline & EAM 56- Gosto da aparência física da minha casa. & 1,0 \\
\hline & EAM 59- Sinto falta de natureza ao redor da minha casa. & $-0,14$ \\
\hline \multirow{6}{*}{$\begin{array}{l}\text { Processo Psicológico: } \\
\text { aspectos afetivos }\end{array}$} & EAM 16- Sinto falta da minha casa quando estou longe & 1,0 \\
\hline & EAM 23- Eu sofreria muito se eu tivesse que sair da minha casa & 1,0 \\
\hline & EAM 40- Gosto da minha casa. & 1,0 \\
\hline & EAM 48- Me sinto feliz em morar nessa casa. & 1,0 \\
\hline & EAM 55- Tenho orgulho de morar nessa casa. & $-0,14$ \\
\hline & EAM 61- Me sinto ligado a minha casa. & $-0,42$ \\
\hline
\end{tabular}




\begin{tabular}{|c|c|c|}
\hline \multirow{10}{*}{$\begin{array}{l}\text { Processo Psicológico: } \\
\text { aspectos cognitivos }\end{array}$} & EAM 1- A minha casa é meu porto seguro. & 1,0 \\
\hline & EAM 7- Minha casa significa minha privacidade. & $-0,14$ \\
\hline & EAM 26- Essa casa é o meu lugar de descanso. & 1,0 \\
\hline & EAM 29- A minha casa significa meu lar. & $-0,42$ \\
\hline & EAM 32- Prefiro morar nessa cassa do que em outro lugar. & 1,0 \\
\hline & EAM 36- Morar nessa casa é perigoso. & $-0,42$ \\
\hline & EAM 46- A minha casa significa muito para mim. & $-0,42$ \\
\hline & EAM 47- Morar nessa casa é seguro. & $-0,42$ \\
\hline & EAM 60- Eu me identifico com as pessoas que moram aqui. & $-0,14$ \\
\hline & EAM 67- Essa casa é confortável. & 1,0 \\
\hline \multirow{9}{*}{$\begin{array}{l}\text { Processo Psicológico: } \\
\text { aspectos } \\
\text { comportamentais }\end{array}$} & EAM 20- Mantenho meu terreno limpo. & 1,0 \\
\hline & EAM 22- Quando saio de casa quero voltar o mais rápido possível & 1,0 \\
\hline & EAM 37- Reconstruo minha casa depois que a chuva estragou. & 1,0 \\
\hline & EAM 38- Gostaria de morar em outra casa. & $-0,14$ \\
\hline & EAM 50- Ajudei a construir essa casa. & 1,0 \\
\hline & EAM 52- Seria difícil para eu me acostumar em outra casa. & 1,0 \\
\hline & EAM 58- Mantenho essa casa limpa & $-0,42$ \\
\hline & EAM 65- Defendo minha casa de possíveis ameaças. & $-0,42$ \\
\hline & EAM 66- Gostaria de passar mais tempo nessa casa. & $-0,14$ \\
\hline
\end{tabular}

Conforme demonstrado no quadro 2,32 itens não foram considerados essenciais perante a análise dos juízes. Todos os referidos itens encontram-se destacados com o resultado negativo, pois menos da metade dos juízes consideram como itens relevantes para a mensuração do construto. Desse modo, foram realizadas as exclusões de sete itens respectivamente da subdimensão 'Pessoa: aspectos culturais' e da subdimensão 'Pessoa: aspectos individuais'. Seis itens não foram relevantes da subdimensão 'Processo Psicológico: aspectos cognitivos', cinco itens do 'Processo Psicológico: aspectos comportamentais', três da subdimensão 'Lugar: aspectos físicos' e dois respectivamente das subdimensões 'Lugar: aspectos sociais' e 'Processo Psicológico: aspectos afetivos'.
Em seguida, foi realizada a análise do Kappa de Cohen (k), de modo a identificar a magnitude da concordância dos juízes da escala preliminar composta por 36 itens. A referida análise avalia o grau de acordo e, consequentemente, a confiabilidade da classificação dos juízes ${ }^{21}$. Para realizar a análise do Kappa, foi utilizada como gabarito a avaliação do pesquisador principal da pesquisa, a fim de permitir comparação com as demais análises, conforme demonstrado na tabela 1 , posteriormente, avaliou-se a magnitude de concordância entre os juízes acerca da identificação da subdimensão em que o item representava, como evidencia-se na tabela 2 . 
Tabela 1. Frequência das categorias dos juízes (36 itens)

\begin{tabular}{|c|c|c|c|c|c|c|c|c|}
\hline Dimensão: subdimensão & Gabarito & Juiz 1 & Juiz 2 & Juiz 3 & Juiz 4 & Juiz 5 & Juiz 6 & Juiz 7 \\
\hline Pessoa: aspectos individuais & 3 & 1 & 4 & 7 & 5 & 5 & 6 & 5 \\
\hline Pessoa: aspectos culturais & 5 & 1 & 1 & 5 & 0 & 0 & 0 & 0 \\
\hline Lugar: aspectos sociais & 6 & 5 & 5 & 6 & 5 & 5 & 6 & 4 \\
\hline Lugar: aspectos físicos & 10 & 5 & 11 & 8 & 13 & 6 & 11 & 12 \\
\hline Processo Psicológico: aspectos afetivos & 4 & 6 & 4 & 2 & 4 & 5 & 5 & 4 \\
\hline Processo Psicológico: aspectos cognitivos & 4 & 12 & 9 & 5 & 7 & 12 & 5 & 7 \\
\hline $\begin{array}{l}\text { Processo Psicológico: aspectos comporta- } \\
\text { mentais }\end{array}$ & 4 & 6 & 2 & 3 & 2 & 3 & 3 & 7 \\
\hline Total & 36 & 36 & 36 & 36 & 36 & 36 & 36 & 36 \\
\hline
\end{tabular}

Tabela 2. Kappa combinado e por subdimensão

Kappa combinado e por subdimensão $(n=36)$

Kappa (k)

Pessoa: aspectos individuais

Pessoa: aspectos culturais

Lugar: aspectos sociais

Processo Psicológico: aspectos afetivos

Processo Psicológico: aspectos cognitivos

Processo Psicológico: aspectos comportamentais

A distribuição dos itens mostrou que houve uma discrepância nas categorizações dos juízes, em relação ao gabarito, principalmente no que concerne à subdimensão 'Pessoa: aspectos culturais', corroborando o resultado do Kappa que obteve uma concordância ruim. Essa subdimensão foi a que mais teve itens considerados como irrelevantes pelos juízes. Na coluna destinada às observações, os juízes relataram dificuldade em codificar os itens em suas respectivas subdimensões devido ao modelo teórico tripartite do apego ao lugar ter algumas características e definições semelhantes. Já o fator que teve mais consonância entre os juízes foi o 'Lugar: aspectos físicos', indo ao encontro do resultado encontrado pelo RVC de modo a obter um Kappa moderado ante as demais subdimensões.

A partir do índice de Kappa geral, verificou-se que houve um acordo razoável entre os juízes. Analisando as subdimensões, identificou-se que 'Processo Psicológico: aspectos afetivos', 'Pessoa: aspectos individuais' e 'Lugar: aspectos físicos' obtiveram uma concordância 
moderada $(\mathrm{k}=0,41$ a 0,53$)$. As subdimensões 'Processo Psicológico: aspectos comportamentais', 'Processo Psicológico: aspectos cognitivos' e 'Lugar: aspectos sociais' demonstraram haver um acordo regular entre os juízes ( $\mathrm{k}=$ 0,28 a 0,38). Já a 'Pessoa: aspectos culturais' demonstrou discordância $(\mathrm{k}=-0,004)$, pois os juízes tiveram dificuldades em entender os atributos dessa subdimensão, assim como identificar entre os itens características que seriam culturais a esse grupo, mesmo havendo a explicação no documento enviado.

\section{Análise semântica}

Todos os sujeitos da pesquisa que participaram da análise semântica possuíam casa própria, moravam em média 11 anos na residência, já tinham sido afetados por pelo menos um desastre, sendo 21 deles atingidos por três desses eventos. Quanto ao grau de escolaridade: 19 dos participantes possuíam ensino fundamental incompleto; 5 , ensino médio incompleto; 3 , ensino médio completo; 2 , ensino fundamental completo; e 1 dos participantes era analfabeto. 20 participantes eram mulheres, e 10, homens. Acerca da faixa etária, 13 participantes tinham entre 18 anos e 28 anos; 6, entre 51 anos e 61 anos; 5 participantes tinham de 29 a 39 anos; 4, de 62 a 72 anos; e 2, de 40 a 50 anos. A renda per capita é, em média, de $\mathrm{R} \$ 690$, menor que um salário-mínimo. Evidencia-se a baixa renda econômica dos participantes.

No tocante à compreensão, à clareza dos itens e ao formato da escala apresentada, destaca-se que os participantes tiveram dificuldade em entender as palavras voltadas à estrutura da escala tipo Likert, sendo elas de 'Discordo Totalmente' a 'Concordo Totalmente'. Foi sugerida a substituição dos rótulos da escala por 'não muito', 'não pouco', ‘mais ou menos', ‘sim pouco' e 'sim muito', a fim de que eles pudessem entender melhor o que era solicitado.

Além do formato da escala, um item foi avaliado como vago ('a localização dessa casa me deixa insegura'), sendo solicitado alterá-lo, por não deixar claro o tipo de risco que a população podia correr. Os participantes questionaram se a sensação de insegurança se referia aos assaltos, tráfico ou à ocorrência de desastres. Desse modo, o item foi alterado e descrito da seguinte maneira: 'sinto-me inseguro (a) em morar em uma área que pode ocorrer desastres'.

Quanto à exclusão de itens, salienta-se que um item ('avisamos uns aos outros quando a água é cortada') representou a característica somente de uma parte dos participantes que residiam em área de risco. Em um dos municípios em que foi realizada a coleta de dados, os participantes tinham a escritura das casas. Desse modo, a ação de cortar a água como medida 'punitiva' para que as pessoas saíssem de suas casas não ocorria nesse município.

Acerca dos efeitos teto e chão, foi identificado que os participantes tenderam à resposta em dois itens para o 'sim muito', ocorrendo efeito teto, ou seja, quando mais de $80 \%$ dos participantes assinalam tal alternativa como resposta. Um dos itens denotava a crença religiosa ('Pessoa: aspectos culturais'), de modo a descrever 'essa casa é um presente de Deus'. $\mathrm{O}$ outro item voltado à importância de ter acesso ao saneamento básico (Lugar: aspectos físicos) de modo a relatar 'considero importante ter esgoto tratado em minha casa'. Tais itens foram excluídos. Assim, dos 36 itens decorrentes da análise dos juízes, foram excluídas mais três afirmações na análise semântica para obter uma escala preliminar com 33 itens. Tal escala apresentou evidências de validade baseadas no conteúdo dos itens, uma vez que eles tiveram uma equivalência semântica e contextual, conforme pode ser verificado no quadro 3 . 
Quadro 3. Escala de apego à moradia em área de risco com evidências de validade de conteúdo

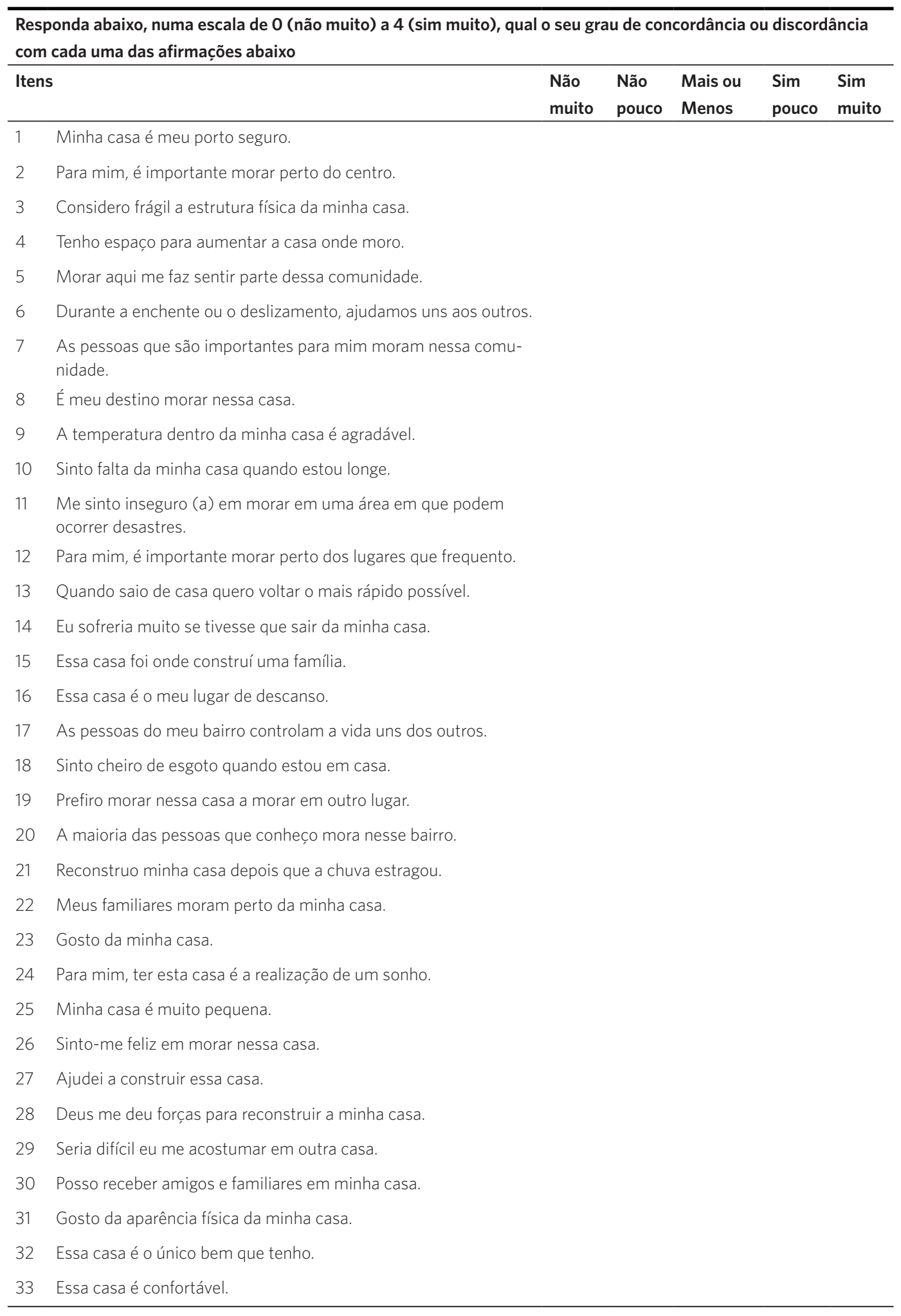

Fonte: Elaboração própria. 


\section{Discussão}

Na análise da RVC, 36 itens foram considerados como relevantes, e 32 itens como irrelevantes. As subdimensões que mais tiveram itens excluídos nesta análise voltavam-se aos aspectos culturais e individuais da pessoa, assim como aos aspectos cognitivos referentes ao processo psicológico proveniente da relação pessoa-lugar. Esses resultados são corroborados pela discordância entre os juízes na análise do Kappa de Cohen (k). No Kappa geral, houve um acordo razoável entre os juízes, o que demonstra pouca concordância entre eles. Tal resultado poderá ter ocorrido pela sobreposição conceitual entre as três subdimensões que acabam refletindo nos itens, pois a subdimensão 'Pessoa: aspectos individuais' traz características voltadas às experiências pessoais, marcos, metas que a pessoa teve com a moradia, assim como a faceta 'Pessoa: aspectos culturais' reflete os valores, os aspectos culturais relacionados com a casa; e a subdimensão 'Processo Psicológico: aspectos cognitivos' reflete as crenças das pessoas sobre a moradia, as quais estão interrelacionadas com os valores e experiências pessoais ${ }^{9} \mathrm{da}$ pessoa com a sua casa. Assim, evidencia-se a dificuldade que os juízes tiveram ao escolher somente uma subdimensão que representassem o item, pois tais características, a partir do modelo teórico, estão interligadas e, em alguns momentos, sobrepostas. Pasquali16 salienta a necessidade de operacionalização do modelo teórico para elaboração dos itens. Quando o modelo teórico dificulta sua operacionalização, irá refletir na estrutura e semântica dos itens de modo a evidenciar uma necessidade de revisão do próprio modelo teórico, como ocorrido neste estudo. Este processo contribui para o aprimoramento do próprio construto.

Já as subdimensões 'Processo Psicológico: aspectos afetivos', 'Pessoa: aspectos individuais' e 'Lugar: aspectos físicos' obtiveram uma concordância moderada. Infere-se que tais subdimensões tiveram maior concordância diante das demais devido às definições destas facetas terem características mais distintas entre os demais atributos. Consequentemente, os itens podem ter sido mais claros para os juízes, principalmente no que concerne ao 'Lugar: aspectos físicos', ao qual atribuem-se características físicas e simbólicas ao lugar. As características físicas voltam-se aos aspectos de infraestrutura do lugar, sendo essa definição clara, concreta e não semelhante com as demais subdimensões. Já os atributos simbólicos do lugar assemelham-se às características da faceta 'Processo Psicológico: aspectos cognitivos', a qual possui processos básicos, tais como a memória e as crenças que contribuem para a construção do significado da moradia ${ }^{10}$. Essa semelhança conceitual contribuiu para o acordo razoável entre os juízes na subdimensão 'Processo Psicológico: aspectos cognitivos'. Esse resultado também foi evidenciado no 'Lugar: aspectos sociais' e 'Processo Psicológico: aspectos comportamentais'. Acredita-se que a faceta 'Processo Psicológico: aspectos comportamentais' tenha obtido esse resultado pela elaboração de alguns itens não terem expressado com clareza os atributos voltados à proximidade, à manutenção e à reconstrução do lugar.

Já a faceta 'Pessoa: aspectos culturais' demonstrou discordância entre os juízes. Hipotetiza-se que esse resultado evidencie a proximidade conceitual de duas subdimensões. A 'Pessoa: aspectos culturais' caracteriza-se como significados do lugar que são compartilhados pelo grupo, tais como: eventos históricos, crenças, valores transgeracionais, ou outra construção simbólica compartilhada entre a comunidade. No 'Lugar: aspectos sociais', há duas maneiras de pensar este apego: uma como sendo o vínculo com as pessoas que convivem naquele lugar, das quais compartilham situações em comum; e a outra forma seria o apego devido à possibilidade de contato social com as outras pessoas que residem no entorno da moradia $^{10}$. Ambas as subdimensões denotam a interrelação da pessoa com a sua comunidade, podendo haver uma sobreposição conceitual.

Na análise semântica, foi realizada uma sugestão acerca da semântica das categorias 
de respostas da escala. Hipotetiza-se que essa sugestão seja corroborada pelo fato de 20 dos 30 participantes não possuírem ensino fundamental completo. Essa sugestão torna-se importante para que a população-alvo possa compreender a magnitude das categorias e, assim, consiga responder à escala. Além disso, um item teve sua escrita alterada, e três itens foram excluídos. Tais alterações da escala evidenciam a importância da busca por evidências de validade baseadas no conteúdo dos itens de modo a oportunizar voz as pessoas que serão o foco da escala; ao passo que este procedimento não foi identificado na pesquisa de Magalhães e Calheiros ${ }^{25}$, as quais também buscaram tal evidência para uma escala de apego ao lugar adaptada. Já Budruk ${ }^{26}$ realizou análise fatorial confirmatória para verificar a semântica dos itens da escala de apego ao lugar adaptada por meio da equivalência de linguagem cruzada da escala na versão em inglês e em Marathi, porém, o índice do modelo teórico não apresentou um bom ajuste, como tem sido verificado nesta pesquisa.

\section{Considerações finais}

Esta pesquisa elaborou uma escala de apego à moradia em área de risco e buscou evidências baseadas no conteúdo dos itens para que tais afirmações tivessem uma equivalência semântica e contextual. Sobre o modelo teórico utilizado para elaborar os itens, salienta-se que houve dificuldades na operacionalização e descrição destes por haver características das subdimensões semelhantes, tais como 'Pessoa: aspectos culturais' e 'Lugar: aspectos sociais', 'Lugar: aspectos físicos' e 'Processo Psicológico: aspectos cognitivos'. Outro aspecto a ser destacado refere-se ao desafio ao construir itens que separassem a pessoa de seu processo psicológico, pois, quando um item é elaborado, deve expressar uma manifestação do comportamento, e o comportamento em si já era uma subdimensão. A referida dificuldade também foi expressa pelos juízes a partir dos resultados de suas avaliações, de modo que na RVC, foram considerados 32 itens como irrelevantes, e no índice de Kappa, obteve-se um acordo razoável entre os juízes. A subdimensão 'Pessoa: aspectos culturais' foi a faceta que mais demonstrou discordância entre os juízes, salientando a necessidade de rever os itens, assim como o modelo teórico tripartite do apego ao lugar.

Já a análise semântica foi um aspecto essencial para obter evidências voltadas ao conteúdo dos itens, pois necessitou rever os rótulos da escala tipo Likert, a escrita de um item, assim como teve-se que excluir afirmações que tendiam à resposta para um rótulo. Tal procedimento contribui para que a escala, após alterações, fosse clara e estivesse de acordo com a perspectiva da população-alvo.

No que concerne à limitação deste estudo, destaca-se o não detalhamento sobre o que é uma área de risco, pois alguns juízes não compreenderam as vivências culturais das pessoas que residiam em um lugar suscetível à ocorrência de desastres. Sugere-se que, para as pesquisas da área da psicologia ambiental e relações pessoa-ambiente que buscam evidências de validade baseadas no conteúdo de escalas elaboradas, sejam delimitadas de maneira clara as características do lugar que será foco do instrumento, a fim de contribuir para a avaliação dos juízes do instrumento de medida.

Outras limitações do estudo foram os resultados do Kappa de Cohen, os quais apresentaram somente em três subdimensões concordância moderada. Tal resultado pode ter ocorrido pela sobreposição conceitual entre as subdimensões que acaba refletindo nos itens, assim como por ter sido solicitada aos juízes a avaliação das subdimensões ao invés das dimensões do construto. Os resultados evidenciaram a necessidade da revisão do modelo teórico, assim como de sua testagem empírica. Sugere-se a continuidade do desenvolvimento desta pesquisa, principalmente quanto à busca de evidências de validade voltadas à estrutura interna dos itens por meio da análise fatorial, a fim de testar e aprimorar o modelo teórico tripartite de Scannell e Gifford ${ }^{10}$. Além disso, 
sugere-se a utilização da Teoria de Resposta ao Item a fim de verificar o nível de dificuldade dos itens. Destaca-se também a necessidade da verificação de outros parâmetros psicométricos, tais como evidências de validade relacionadas com outras variáveis e indicadores de precisão.

A partir desses resultados, demonstrou-se que a escala de apego à moradia em área de risco possui evidências iniciais baseadas no conteúdo dos itens, de modo que 33 itens representaram as características do construto apego ao lugar. Identificaram-se somente dois estudos publicados que demonstraram a aplicabilidade dessa fonte de evidência, assim como não foram encontradas pesquisas que utilizaram o mesmo modelo teórico para elaborar uma medida de apego ao lugar, o que dificultou o diálogo com outros estudos. Em contrapartida, evidencia-se a relevância desta pesquisa.

\section{Colaboradores}

Alves RB (0000-0002-1866-699X)*, Kuhnen A (0000-0001-9635-9306)* e Cruz RM (00000003-4671-3498)* contribuíram igualmente na realização das seguintes atividades: 1) concepção e o planejamento do manuscrito, assim como análise e a interpretação dos dados; 2) elaboração do manuscrito e revisão crítica do conteúdo; e 3) aprovação da versão final do manuscrito.

\section{Referências}

* Orcid (Open Researcher and Contributor ID).
1. Dourado F, Arraes TC, Silva MF. O Megadesastre da Região Serrana do Rio de Janeiro: as causas do evento, os mecanismos dos movimentos de massa e a distribuição espacial dos investimentos de reconstrução no pós-desastre. Anu. Inst. Geocienc. 2012; 35(2):43-54.

2. Vargas D. "Eu fui embora de lá, mas não fui”: a construção social da moradia de risco. In: Valencio N, Siena M, Marchezini V, et al. Sociologia dos desastres construção, interfaces e perspectivas no Brasil. São Carlos: RiMa; 2009. p. 80-95.

3. Junges AE, Schadeck R. Desafios do mapeamento das áreas de risco. Cad. Percebendo Risc. Prev. Perdas. 2010; (30):154-162.
4. Guimarães RB, Guerreiro JAS, Peixoto JAS. Considerações sobre os riscos ambientais e urbanos no tocante aos desastres e emergências. Rev. Vera Cidade. 2008;3(3):1-12.

5. Brasil. Ministério da Integração Nacional. Política Nacional de Defesa Civil. Brasília, DF: Ministério da Integração Nacional; 2007.

6. Alves RB, Lacerda MAC, Legal EJ. A atuação do psicólogo diante dos desastres naturais: uma revisão. Psicol. em Estudo. 2012; 17(2):307-31

7. Favero E, Sarriera JC, Trindade MC. O Desastre na Perspectiva Sociológica e Psicológica. Psicol. em Estudo. 2014; 19(2):201-209. 
8. Alves RB, Kuhnen A, Battiston M. "Lar Doce Lar": Apego ao Lugar em Área de Risco diante de Desastres Naturais. Psic. 2015; 46(2):159-168.

9. Günther H. Reflexões sobre a sustentabilidade da Psicologia Ambiental no Brasil. In: Tassara E, Rabinovitch E, Guedes M. Psicologia e Ambiente. São Paulo: Educ; 2004. p. 119-131.

10. Scannell L, Gifford R. Defining place attachment: A tripartite organizing framework. J. of Environmental Psyc. 2010; (30):1-10.

11. Hauck F, Zanon C. Questões básicas sobre mensuração. In: Hutz CS, Bandeira DR, Trentini CM. Psicometria. Porto Alegre: Artmed; 2015. p. 23-43.

12. Pacico JC, Hutz CS. Validade. In: Hutz CS, Bandeira DR, Trentini CM. Psicometria. Porto Alegre: Artmed; 2015. 71-84.

13. Gil AC. Como elaborar projetos de pesquisa. 6. ed. São Paulo: Atlas; 2017.

14. Fonseca JJS. Metodologia da pesquisa científica. Fortaleza: UEC; 2007.

15. Dancey CP, Reidy J. Estatística sem matemática para a Psicologia. 5. ed. Porto Alegre: Artmed; 2013.

16. Bartilotti CB. Fatores da Senso-percepção relacionados à atividade do condutor no sistema trânsito: construção e validação de um instrumento de medida [tese]. Florianópolis: Universidade Federal de Santa Catarina; 2009. p. 153.

17. Pasquali L. Psicometria: Teoria dos testes na Psicologia e na Educação. In: Validade dos testes. Petrópolis: Vozes; 2013. p. 158-191.

18. Pasquali L. Princípio de Elaboração de Escalas Psicológicas. Rev. Psiq. Clínic. 1998; 25(5):206-2013.
19. Cohen RJ, Swerdlick ME, Sturman ED. Testagem e avaliação psicológica: introdução a testes e medidas. 8. ed. Porto Alegre: AMGH; 2014.

20. Lawshe CH. A quantitative approach to contente validity. Perso. Psyc.1975; 28(4):563-575.

21. Landis JR, Koch GG. The measurement of observer agreement for categorical data. Bio. 1977; (33):159-174

22. Fonseca R, Silva P, Silva R. Acordo inter-juízes: O caso do coeficiente kappa. Laboratório de Psicologia. 2007; 5(1):81-90.

23. Cozby PC. Métodos de pesquisa em ciências do comportamento. São Paulo: Atlas; 2003.

24. Ruiz BH, Villodres MC, Vilela LD. Predictores de apego al lugar. In: Sabucedo JM, García-Mira R, Ares E, et al. Libro de comunicaciones. Barcelona: Publicacions Barcelona; 1998. p. 39-45.

25. Magalhães E, Calheiros MM. Psychometric properties of the Portuguese version of place attachment scale for youth in residential care. Psicothema. 2015; 27(1):65-73.

26. Budruk M. Cross-Language Measurement equivalence of the Place Attachment Scale: a multigroup confirmatory factor analysis approach. J. of Leisure Research. 2010; 42(1):25-42.

Recebido em 30/04/2019

Aprovado em 11/09/2019

Conflito de interesses: inexistente

Suporte financeiro: não houve 